\title{
Just Visiting: A Working Concept of "Wilderness" for Environmental Ethics and Ordinary Language Raquel Robles
}

\begin{abstract}
This paper argues for retaining the concept of "wilderness" as a significant ethical category and considers arguments by J. Baird Callicott and William Cronon for abandoning it. Counters by Paul M. Keeling and Scott Friskics are evaluated and defended. Lastly, the paper recommends thinking of the term "wilderness" as belonging to a certain range of meanings on a spectrum of naturalness.
\end{abstract}

\section{A Brief History of the Term Wilderness}

The evolution of the concept of wilderness is commonly understood as a shift from wilderness being thought of as a dangerous place to being thought of as a resource for human use. ${ }^{1}$ This shift is due to the change in culture over time. Before the Industrial Revolution in America, wilderness had no value independent of humans. When Romanticism became popular in the United States, "wilderness" began to be understood in a way that resembles what is commonly thought of today. People started to value wilderness as an escape from industrialized society. Writers like Emerson, Thoreau, and Muir argued that wilderness was God's Cathedral, and that it was healthy for the human spirit to escape the civilized world and return to wilderness. Human action upon nature was considered to be negative. Many painters and writers at the time advocated for an escape to wilderness and valued it for more than just its ability to be harvested as resources. By the late $19^{\text {th }}$ century the U.S. began to establish the first National Parks.

The Wilderness Act of 1964 is considered to be a significant accomplishment for environmentalists who wanted wilderness areas to be preserved. It was aimed to "establish a National Wilderness Preservation System for the permanent good of the whole people,

'Roderick Nash, Wilderness and the American Mind (New Haven, Conn.: Yale UP, 1982). 
and for other purposes." 2 These wilderness areas were to be set aside for recreational and possible future use by the U.S. The wilderness definition as stated in the Wilderness Act of 1964 has been widely accepted by many philosophers as the definition of wilderness. It states:

A wilderness, in contrast with those areas where man and his own works dominate the landscape, is hereby recognized as an area where the earth and its community of life are untrammeled by man, where man himself is a visitor who does not remain. An area of wilderness is further defined to mean in this Act an area of undeveloped Federal land retaining its primeval character and influence, without permanent improvements or human habitation, which is protected and managed so as to preserve its natural conditions and which (1) generally appears to have been affected primarily by the forces of nature, with the imprint of man's work substantially unnoticeable; (2) has outstanding opportunities for solitude or a primitive and unconfined type of recreation; (3) has at least five thousand acres of land or is of sufficient size as to make practicable its preservation and use in an unimpaired condition; and (4) may also contain ecological geological, or other features of scientific, educational, scenic, or historical value. $^{3}$

Callicott cites this definition of wilderness from the Wilderness Act, but argues that: "This definition assumes, indeed it enshrines, a bifurcation of man and nature." ${ }^{4}$ However, this humannature dichotomy is not explicitly supposed in the Wilderness Act. It makes more sense to read the Wilderness Act as allowing humans to be a part of wilderness. It is important to note that nowhere does the wilderness act explicitly say that wilderness is that place where humans cannot exist. "In contrast with those areas where man and his own works dominate the landscape," "where man himself is a visitor who does not remain," and "with the imprint of man's work substantially unnoticeable" 5 are some examples of phrases that allow

\footnotetext{
${ }^{2}$ Carl Levin, "The Wilderness Act of 1964," The Great New Wilderness Debate: An Expansive Collection of Writings Defining Wilderness from John Muir to Gary Snyder, ed. J. Baird Callicott and Michael P. Nelson (Athens: U of Georgia, 1998), 121.

${ }^{3}$ Ibid., 121.

${ }^{4}$ J. Baird Callicott, "The Wilderness Idea Revisited: The Sustainable Development Alternative," The Great New Wilderness Debate, 349.

${ }^{5}$ Levin, "The Wilderness Act of 1964," 121.
} 
for humans to be a part of wilderness. Man is allowed to be a part of the wilderness, he just cannot be the dominating force.

\section{Arguments For and Against the Use of the Term "Wilderness"}

The first common argument philosophers pose against using the term "wilderness" in environmental ethics is that it perpetuates an outdated notion that there exists a human-nature dichotomy. An example of this argument is presented by Cronon: "This, then, is the central paradox: wilderness embodies a dualistic vision in which the human is entirely outside the natural. If we allow ourselves to believe that nature, to be true, must also be wild, then our very presence in nature represents its fall." "According to Darwinian thought, if humans are a part of nature why aren't their creations also a part of nature? Callicott argued in his article: "If man is a natural, a wild, and evolving species, not essentially different in this respect from all the others, as Gary Snyder reminds us, then the works of man, however precious, are as natural as those of beavers, or termites, or any of the other species that dramatically modify their habitats."

Before evaluating this argument, it is important to help clarify the use of another term in many of these writings, namely "nature." Like many words we use in ordinary language, "nature" has a range of meanings. The two most important to this discussion are: (1) the primitive natural world that exists without human interference and (2) the natural world with all of its living things. These definitions of nature are sometimes used by philosophers interchangeably when defining wilderness, when in reality they are referring to two seemingly different concepts. This twofold definition of "nature" makes it seem as if there exists a paradox in the wilderness concept, since nature is often used in defining wilderness. We can agree that using "nature" to refer to the primitive natural world that exists without human interference, and the term used to refer to the natural world with all of its living things, cannot be used interchangeably because humans exist as a part of one definition and not the other. The incoherence that some philosophers suggest occurs in the wilderness definition is rather a problem of equivocation between two different concepts of nature.

\footnotetext{
${ }^{6}$ William Cronon, "The Trouble with Wilderness; Or, Getting Back to the Wrong Nature," Environment: An Interdisciplinary Anthology, ed. Glenn Adelson (New Haven: Yale UP, 2008), 302.

${ }^{7}$ Callicott, "The Wilderness Idea Revisited," 350.
} 
In Cronon's first statement, that man is opposite from nature, he is supposing that "wilderness" involves the definition of "nature," that is, the primitive natural world that exists without human interference. Cronon then continues to argue: "If we allow ourselves to believe that nature, to be true, must also be wild, then our very presence in nature represents its fall." $8 \mathrm{He}$ is arguing that if "wilderness" assumes humans are opposite from nature, simply having them in these wilderness areas takes away those areas' wildness. If we were to define wilderness in the way that Cronon seemingly does, then there is a paradox present in the wilderness definition of the Wilderness Act when it suggests that humans can visit nature.

According to Friskics, Cronon is defining wilderness in a way that resembles that of the nineteenth century: "This idea conceives of wilderness as a 'pristine' or 'virgin' nature unsullied by the damaging influence of humankind." "The more widely recognized definition of wilderness today is that which is consistent within the Wilderness Act. This definition does not perpetuate the humannature dichotomy, however. The Wilderness Act allows for humans to have a place within wilderness. Friskics notes that, "Wilderness areas are places without 'permanent ... human habitation."."10 "According to the [Wilderness] Act, wilderness is a place we visit, not a place where we establish permanent residence." 11 Just because humans are unable to set up residence in wilderness areas does not mean they are not allowed in them. This definition of "wilderness" implicates the definition of "nature" as the natural world and all its living things since humans are not absent from nature and in this case, wilderness. Friskics follows up with: "In wilderness areas, human influences are not absent; they are just minimized. Like everything else about wilderness, it is not a question of human or natural, but a matter of degree." 12 Since Cronon's definition of wilderness is outdated, we can argue that our current concept of wilderness does not suffer from the human-nature dichotomy.

Another common philosophical argument is that "wilderness" is ethnocentric. Callicott reasons that since many early wilderness writers consider Native Americans as a part of wilderness and settlers as disruptions of wilderness, the term is inherently prejudicial.

\footnotetext{
${ }^{8}$ Cronon, "The Trouble with Wilderness," 302.

${ }^{9}$ Scott Friskics, "The Twofold Myth of Pristine Wilderness," Environmental Ethics 30, no. 4 (Winter 2008): 382.

${ }^{10}$ Levin, 121.

${ }^{11}$ Friskics, "The Twofold Myth of Pristine Wilderness," 385.

${ }^{12}$ Ibid.
} 
Callicott argued: "[u]pon the eve of European landfall most of temperate North America was not . . . in a wilderness conditionnot undominated by the works of Man-unless one is prepared to ignore the existence of its aboriginal inhabitant and their works or to insinuate that they were not 'man,' i.e., not fully human beings." 13 He reasoned that Native Americans have significantly altered the environment around them, but since this impact was different than what the settlers were accustomed to, it was still considered wilderness. These nature writers accepted that Native Americans were a part of wilderness because they believed Native Americans had little impact or were primitive, like the animal inhabitants of the wilderness. The traditional concept of wilderness therefore is unacceptably ethnocentric, placing differential value on activities of some humans over others.

This argument is valid if one assumes the notion of wilderness that presupposes that no human activity is allowed in the wilderness. If you were to accept that definition, and that Native Americans were a part of wilderness, you would in fact be insisting that they were less than human. While it is true that the definition of wilderness, as Callicott is interpreting it in this section, is inherently racist, this is not the case for the concept of wilderness that the Wilderness Act puts forward. The current conception of wilderness allows for humans to have a role in the wilderness as long as it, "generally appears to have been affected primarily by the forces of nature, with the imprint of man's work substantially unnoticeable." 14

Another argument is presented by Callicott was that the definition of wilderness ignores the fact that natural areas are everchanging. He argues that when the concept of wilderness is used in environmental ethics, it implies a goal of freezing the natural processes to the condition it is in now. He thinks this is problematic because in managing "wilderness" we are treating natural processes as static rather than as the dynamic processes they are. We are not allowing the natural processes to take their course by managing preserved areas because, "[e]cological succession is continually reset by one or another natural disturbance." 15

Friskics responds by arguing "that the idea that, once designated, wilderness areas will maintain themselves in a state of self-perpetuating equilibrium is a myth." ${ }^{16} \mathrm{He}$ argues that even

\footnotetext{
${ }^{13}$ Callicott, 352.

${ }^{14}$ Levin, 121.

${ }^{15}$ Callicott, 354.

${ }^{16}$ Friskics, 396.
} 
though natural areas are dynamic by nature we have to manage them in order to maintain their "wilderness character." Since the areas surrounding the wilderness have both been radically altered by human activity and are strictly managed, we must help to facilitate natural processes within the wilderness areas. Forest fires, for example, are prevented in the areas surrounding wilderness in order to protect [their] inhabitants. This extreme form of fire prevention necessitates the planned burning of wilderness areas. Since, according to the Wilderness Act, human activity is acceptable when "[wilderness areas] are protected and managed so as to preserve its natural conditions." 17 Therefore the concept of "wilderness" implied in the ethics of preservation and management does not imply that we must preserve wilderness in a static state.

The last argument to be discussed is that wilderness areas are used as an escape from the reality we created in order to avoid responsibility for our non-sustainable actions. According to Cronon, "The core of wilderness represents the false hope of an escape from responsibility, the illusion that we can somehow wipe clean the slate of our past and return to the tabula rasa." ${ }^{18}$ Cronon argues that thinking of wilderness as an example of how the world is supposed to be makes humans escape to this vision that is unattainable. Since humans can use the wilderness as an escape from their artificial lives, there is no incentive for humans to positively impact their lives at home. It "gives us permission to evade responsibility for the lives we actually lead," which is why Cronon argues wilderness is a problematic term for environmental ethics. ${ }^{19} \mathrm{He}$ argues that if we are only our true selves when we are in the wilderness, then when we are in civilization we have no responsibility to live sustainably.

I am sympathetic to this fourth argument, that the old notion of "wilderness" problematically allows us to evade responsibility. I disagree with the source of the problem, however. The problem does not stem from the definition of wilderness itself but rather from our conceptions of both our roles within wilderness and civilization. There needs to be a shift away from valuing wilderness areas because of their absence of humans, and towards an idea that they are valuable because of their ability to let natural processes thrive. I recommend attributing value to the natural processes at work in the wilderness because then we can begin to understand the value of natural

\footnotetext{
${ }^{17}$ Levin, 121.

${ }^{18}$ Cronon, 301.

${ }^{19}$ Ibid., 302.
} 
processes even in our "artificial" world. This will further explain our role in the wilderness as protectors of natural processes. This value system is beneficial because we can take it and extend it to the "artificial" world we live in. If we aim to promote natural systems because they are valuable, then we can start positively impacting where we live to be more sustainable. The value of natural processes can be grounded in a number of ways. Natural processes could be considered valuable intrinsically, for their spiritual relationships, or even instrumentally in that they are necessary for human survival. The exact reason natural processes are valuable does not have to be determined here. It is only important to understand that if we shift the value of wilderness away from its absence of humans towards a place that promotes natural processes, we can better our relationship with both wilderness areas and those places we call home.

\section{A Working Suggestion for the Wilderness Spectrum}

I am sympathetic to the definition of wilderness presented in the Wilderness Act. This definition is good for practical reasons such as its role in aiding the preservation of wilderness areas, but it is not perfect. There are many areas that we would consider to be wilderness that would not be included in the Wilderness Act. For example, many wilderness areas on the East Coast are not, "at least five thousand acres of land." ${ }^{20}$ To achieve a working concept of wilderness, Keeling argues that we should look towards our ordinary language. He took a Wittgensteinian approach to thinking about defining "nature" that I feel should be extended to "wilderness." Keeling argues, "To give meaning of a word is to specify its grammar, which is the system of unarticulated, constitutive rules governing its use." ${ }^{21}$ When constructing our wilderness concept we must first look at all the ways we use the term. When we take these usages into account we become familiar with the "language games" we are playing. We do not need to have one single definition of any word, because in ordinary language the meanings of our words depend on the ways in which we use them. This would allow us to talk about a larger variety of wilderness areas that might not have been included in the Wilderness Act. Keeling raised the idea of a spectrum for different purposes, but I feel "wilderness" would benefit from being defined as part of a spectrum because of its multitude of uses.

\footnotetext{
${ }^{20}$ Levin, 121.

${ }^{21}$ Paul M. Keeling, "Does the Idea of Wilderness Need a Defense?" Environmental Values 17, no. 4 (2008): 509.
} 
The uses of the term "wilderness" should be thought of as lying along a certain portion of the spectrum of "naturalness." In particular, it indicates those forms of naturalness that escape the domination of humans; "wilderness" will refer to those places in which natural processes are allowed to operate on their own. The ideal wilderness would be that place in which natural processes were able to operate independently with no interference by humans. Some philosophers such as Vogel and McKibben would claim that since the ideal end of the spectrum is that place left fully to its own natural processes, and humans have had some kind of impact on every place, there is no ideal wilderness. ${ }^{22}$ While I agree that there is no example of ideal wilderness here on Earth, it is easy to think of distant planets that humans have in no way impacted. Those places could work as the ideal wilderness. Even if the ideal "wilderness" does not exist, it is a valuable concept. Keeling argues that "this empirical objection to wilderness appears to have no more merit than would similar empirical objections to 'freedom,' 'justice,' 'empowerment,' 'cultural diversity,' or almost any other widely or deeply held human ideal, based on such ideals being 'impossible' in practice." ${ }^{23}$ We do not need to have a single definition of a concept in order to use it. We simply need to understand how that concept is being applied. Consequently, we can understand "wilderness" being used to indicate many degrees of "naturalness," including its use in the ideal sense, even if nothing exists that satisfies the concept.

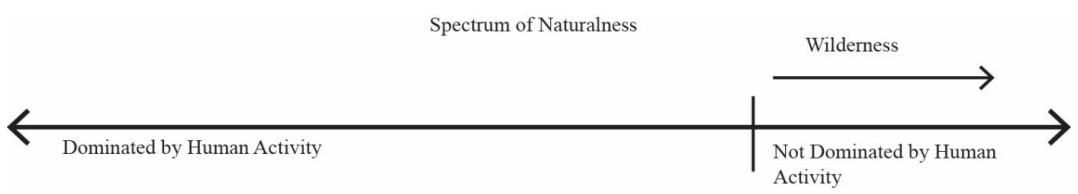

Defining wilderness as a portion of the spectrum of naturalness is not subject to the human-nature dichotomy, because instead of valuing wilderness for its separation from humans it is valued in its concern for "naturalness." Wilderness areas should be visited accordingly, and be used by humans as a place to appreciate our role in protecting the "naturalness" of natural processes. Those places closest to the ideal wilderness will give humans a better

\footnotetext{
${ }^{22}$ Steven Vogel, "Why 'Nature' Has No Place in Environmental Philosophy,” The Ideal of Nature: Debates about Biotechnology and the Environment, ed. Gregory E. Kaebnick (Baltimore: Johns Hopkins UP, 2011).

${ }^{23}$ Keeling, "Does the Idea of Wilderness Need a Defense?," 506.
} 
learning experience as "visitors who do not remain." 24 The idea of acting as visitors who do not remain should become a part of our understanding of our relation to wilderness. This kind of behavior can then be extended to those "ideal" wildernesses in space. If we are able to fully understand ourselves as visitors we would be more likely to go these distant places without spoiling their "wildness."

However, even more importantly, by thinking of ourselves as visitors on the Earth rather than masters over the Earth, we can not only change how we interact with wilderness areas, but also those areas we call home. ${ }^{25}$ The better we are able to understand sustainable living in an attempt to protect natural processes, the more we are able to protect those natural processes that we interact with everyday. This could increase the quality of life by promoting sustainable living in our own communities. By thinking of ourselves as visitors, we are able to show respect to the natural processes that function all around us.

\section{Conclusion}

Many of the arguments put forward by Cronon and Callicott are either based on an outdated definition of wilderness that involves a human-nature dichotomy, or equivocate on two different concepts of "nature." The "Wilderness Act" definition, despite its critics, works well with our current views of the human-nature relationship. However, it does not fully capture the flexibility of our ordinary language concept of "wilderness." It is instead valuable to think of the term "wilderness" as possibly referring to that range on the spectrum of naturalness that is not dominated by humans. This allows for humans to learn about their relationship with natural processes, and be sensitive to "naturalness" outside of wilderness. This concept of wilderness could be valuable to environmental ethics because it can be molded to the types of landscapes present in the community we live. This concept is ultimately better adept than the "Wilderness Act" at allowing natural processes to thrive.

\footnotetext{
${ }^{24}$ Levin, 121.

${ }^{25}$ Many philosophers assume that there is a pervasive belief that we are masters over nature. Mirjam de Groot, Martin Drenthen, and Wouter T. de Groot gathered research and found that, "[m] astery over nature has all but disappeared as anything desirable in the minds of most people in Western societies. Virtually all respondents believe that humans are morally responsible for nature and recognize the intrinsic value of nature." Mirjam de Grootf, Martin Drenthen, and Wouter T. de Groot, "Public Visions of the Human/Nature Relationship and Their Implications for Environmental Ethics," Environmental Ethics 33, no. 1 (Spring 2011): 39.
} 